\title{
Lung Development in the Fetal Guinea Pig: Surfactant, Morphology, and Premature Viability
}

\author{
ILENE R. S. SOSENKO AND LEE FRANK \\ Pulmonary Research Laboratories, Calvin and Flavia Oak Asthma Research and Treatment Facility, \\ Department of Medicine; and Division of Neonatology, Department of Pediatrics, University of Miami School of \\ Medicine, Miami, Florida 33136
}

\begin{abstract}
Guinea pigs demonstrate "precocious" physical and functional development, with newborns displaying open eyes, hair, self-feeding, and temperature regulation. In addition, morphologic lung development is precocious in the guinea pig, with advanced alveolarization taking place in utero. To explore whether pulmonary surfactant development is also advanced, and at what stage prematurely delivered guinea pigs are capable of survival, we delivered fetal guinea pigs at 2- to 3-day intervals from day 49 of gestation to day 69 (birth). These were examined for chronologic changes in lung morphology, lung tissue disaturated phosphatidylcholine, phosphatidylglycerol and glycogen content, and serum glucocorticoid and thyroid hormone levels. Other prematurely delivered guinea pigs were given brief postnatal resuscitation and their survival noted. We confirmed advanced morphologic lung maturation, yet found that surfactant development, with antecedent hormone peaks and glycogen depletion, occurs during the final 10-15\% of gestation. Lung biochemical development is thus "on time" in the guinea pig, rather than "precocious" compared to other frequently studied laboratory animals. In addition, $>50 \%$ of fetal guinea pigs are capable of survival by 8 days prior to term, well in advance of premature survivability in other small-sized species. (Pediatr Res 21: 427-431, 1987)
\end{abstract}

\section{Abbreviations}

DSPC, disaturated phosphatidylcholine

PG, phosphatidylglycerol

TPL, total phospholipids

$\mathrm{T}_{3}$, triiodothyronine

The gestation period of the guinea pig is considerably longer (69 days) than that of other commonly studied small-sized mammals (i.e hamster $\sim 16$ days, rat $\sim 22$ days, rabbit $\sim 31$ days). Associated with this relatively long gestation in the guinea pig is a remarkable degree of physical and functional maturity demonstrated by the newborn of the species. At birth guinea pigs have full coats of hair, open eyes, and the ability to regulate body temperature and to feed apart from the mother (1). Engel (2) hypothesized in 1953 that the lung growth and development of a species should parallel the overall development present at birth. In support of Engel's hypothesis, Lechner and Banchero (3)

Received Oct. 2, 1986; accepted Dec. 4, 1986

Correspondence and reprint requests to llene R. S. Sosenko, M.D., Pulmonary Research R 120, University of Miami School of Medicine, P.O. Box 016960, Miami, FL 33101.

Supported by NIH Grants HL07283 and HL26029 and NHLBI Research Career Development Award HL01230 (LF), March of Dimes Basil O'Connor Grant 5540, and American Lung Association Research Grant (IRSS). found advanced morphologic lung development in the newborn guinea pig.

We questioned whether other aspects of lung development, in addition to lung morphology, would also be accelerated in the developing guinea pig, adding further support to Engel's hypothesis. The present study was undertaken to investigate the following: 1) the developmental pattern of the surfactant system in the fetal guinea pig, 2) how surfactant development is chronologically related to morphologic development in the guinea pig lung, 3 ) whether an endogenous rise or peak in serum glucocorticoid and/or thyroid hormone levels precedes the maturational changes in lung morphology and/or surfactant. Finally, we sought to determine the viability of premature guinea pigs delivered at varying gestational ages, and what degree of lung morphologic and surfactant development would be associated with premature survival.

\section{METHODS}

Timed-pregnancy Camm-Hartley guinea pigs were obtained from Camm Laboratories, Wayne, NJ and maintained on standard laboratory food and water ad libitum. From gestational days 49-67, guinea pig fetuses were delivered at 2- to 3-day intervals by hysterotomy under pentobarbital anesthesia. Newborn guinea pigs (69 days) were obtained after normal parturition and sacrificed with an overdose of pentobarbital.

Lung morphology. Randomly selected guinea pig lungs from each gestational age were inflated via a tracheal cannula with $10 \%$ buffered formalin, using a constant inflation pressure of 20 $\mathrm{cm}$ of water (fixative). From all lungs, similarly oriented sections from each lobe were stained with hematoxylin and eosin and examined for qualitative differences at different gestational ages. We calculated percent air space on coded slides utilizing an integrating grideyepiece with five equal lines and 25 intercept bars (Zeiss) at $\times 450$ magnification. We counted the number of times intercept bars fell on lung tissue and on air spaces per field (with 30 random fields counted on each slide) and percent air space was calculated using the formula

$$
\% \text { air space }=\mathrm{P}_{\mathrm{A}} /\left(\mathrm{P}_{\mathrm{A}}+\mathrm{P}_{\Upsilon}\right) \times 100
$$

where $P_{A}$ is the number of intercept bars hitting air and $P_{T}$ is the number of intercept bars hitting tissue. Both investigators examined all coded slides and their results were averaged.

Lung biochemistry. Other randomly selected fetal and newborn lungs were perfused immediately in situ via the pulmonary artery using cold saline. The perfused lungs were removed, stripped of nonpulmonary tissue, and homogenized in 20-30 times their weight of cold saline in a Brinkman polytron (high speed, 90s). Aliquots of lung homogenate were assayed for protein content (4). Lipid extraction of the lung homogenates was performed according to the method of Bligh and Dyer (5). A portion of lipid extract was submitted to thin-layer chromatog- 
raphy to separate PG as described by Touchstone et al. (6). PG was quantitated from thin layer plates by densitometry. A second portion of lipid extract was used to measure DSPC which was separated from other phospholipids using the procedure of Mason et al. (7) and was assayed for inorganic phosphorus by the method of Morrison (8). A known quantity of ${ }^{14} \mathrm{C}$-dipalmitoylphosphatidylcholine (New England Nuclear, Boston, MA) was added prior to lipid extraction and aliquots counted at each step to estimate and correct for sequential losses. DSPC was expressed as $\mathrm{mg} / \mathrm{g}$ wet lung weight, and $\mathrm{mg} / \mathrm{mg}$ protein. $\mathrm{PG}$ was expressed as percent change from 61-day levels. Additional lungs at each gestational age were rapidly removed, flash-frozen in liquid nitrogen and assayed for glycogen (9). Glycogen was expressed as $\mu \mathrm{g} / \mathrm{g}$ wet lung weight and $\mu \mathrm{g} / \mathrm{mg}$ protein.

Blood samples obtained from random fetuses of gestational days 51 to 62 were assayed for serum total cortisol, corticosterone, and $\mathrm{T}_{3}$ using specific radioimmunoassay test kits (cortisol and $\mathrm{T}_{3}$ : Cambridge Medical Diagnostics, Billerica, MA; corticosterone: Radioassay Systems Laboratories, Carson, CA).

Survival studies. Premature guinea pig fetuses from days 5966 of gestation were delivered by hysterotomy under ketamine:xylazine anesthesia (Ketalar, $90 \mathrm{mg} / \mathrm{kg}$, Parke Davis, Morris Plains, NJ; Rompun, $10 \mathrm{mg} / \mathrm{kg}$, Cutter Labs, Shawnee, KS). Premature pups were resuscitated briefly with heat, stimulation, and low-flow $\mathrm{O}_{2}$ administration until sustained respiration was achieved. Postresuscitation, prematures breathed room air, were returned to surrogate mothers, and were observed carefully for survival over the first $24 \mathrm{~h}$ of life.

Statistics were performed using Student's $t$ test (10).

\section{RESULTS}

Lung morphology. The light microscopic appearance of lungs from guinea pigs at $55,58,63$, and 69 (birth) days of gestation are seen at $\times 450$ magnification in Figure $1(A-D)$. At 55 days of gestation $(A)$ the acinar pattern of development is immature and "canalicular," with thick septae and an airspace:tissue ratio that appears to be about 1:1. By 58 days of gestation (B), dramatic changes have occurred. The acinar pattern now appears more saccular, with decreased tissue density, marked septal thinning, and marked increase in potential airspace. By morphometric calculation the percent airspace was $73.0 \pm 2.2 \%$ at 58 days, significantly different from the 55 day value of $62.2 \pm 2.1 \%, p$ $<0.05$. The morphologic changes which have occurred by 63 days $(C)$ are less dramatic, with further thinning of acinar walls, prominent septal bud formation, and subdivision of the airspaces. Thinning and septation gradually progress from day 63 $(C)$ to day 69 of gestation $(D)$. The percent airspace calculation showed only a gradual increase from the gestational day 58 value over the final 11 days of gestation until birth (percent airspace at birth: $81.2 \pm 0.7 \%$ ).

Lung biochemistry. Lung glycogen and DSPC content are depicted in Figure 2. Glycogen content falls steeply between day $56(33.3 \pm 4.6 \mu \mathrm{g} / \mathrm{mg}$ protein $)$ and day $58(1.27 \pm 0.90 \mu \mathrm{g} / \mathrm{mg}$ protein) ( $p<0.05$ : day 58 versus day 57 values), after which it remains at low levels (at 62 days: $1.15 \pm 0.93 \mu \mathrm{g} / \mathrm{mg}$ protein). DSPC increases gradually from days 49-52 $(0.025 \pm 0.001 \mathrm{mg} /$ $\mathrm{mg}$ protein) to day $61(0.032 \pm 0.005 \mathrm{mg} / \mathrm{mg}$ protein). Day 61 marks the onset of a sharp increase in DSPC with values of 0.058 $\pm 0.004 \mathrm{mg} / \mathrm{mg}$ protein at day 63 ( $p<0.01$ : day 63 versus day 61 values). DSPC does not increase again until just prior to birth (days 67 to 69).

Thin-layer chromatography of lung lipid from guinea pigs ranging from 55 days of gestation to birth as well as adult guinea pigs is seen in Figure 3. No distinct PG spot can be appreciated qualitatively or quantitated by densitometry at gestational days 55 and 58. PG can first be detected by this method in lung tissue

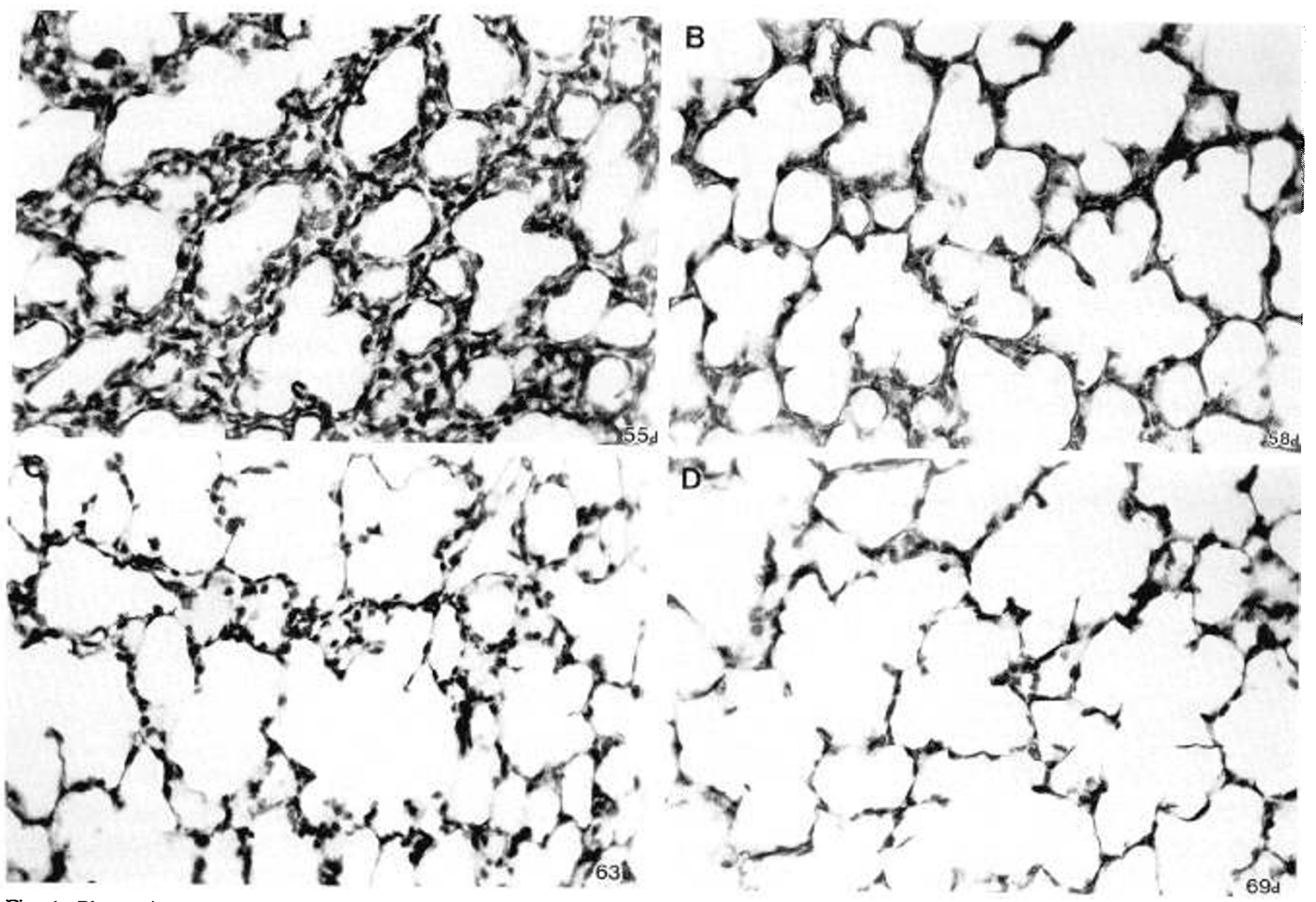

Fig. 1. Photomicrographs of fetal guinea pig lungs from gestational day $55(A)$, day $58(B)$, day $63(C)$, and day 69 -birth $(D)$. Hematoxylin and eosin stain; original magnification $\times 450$. 
at day 61 , after which it continues to increase until the time of birth. Newborn guinea pig lung was found to contain greater quantities of PG (per weight of lung) than adult lung. Changes in lung tissue $P G$ compared to 61 day levels are seen in the bottom part of Figure 4. By 66 days of gestation both PG (Fig. 4) and DSPC (Fig. 2) had increased $>50 \%$ above quantities found in 61-day guinea pigs.

Serum hormones. The serum levels of total cortisol, corticosterone, and $T_{3}$ in fetal guinea pigs from gestational days 51-62 are seen in Figure 5. Both of the glucocorticoid hormones as well as $T_{3}$ appear to have two peaks during this time period. At 54 days of gestation, cortisol, the physiologically important adrenal steroid in the guinea pig, demonstrates an early peak $(p<0.05)$. The earlier peak in $T_{3}$ occurs at 56 days $(p<0.05)$ rather than at 54 days. However, later in gestation at day 59 , all three

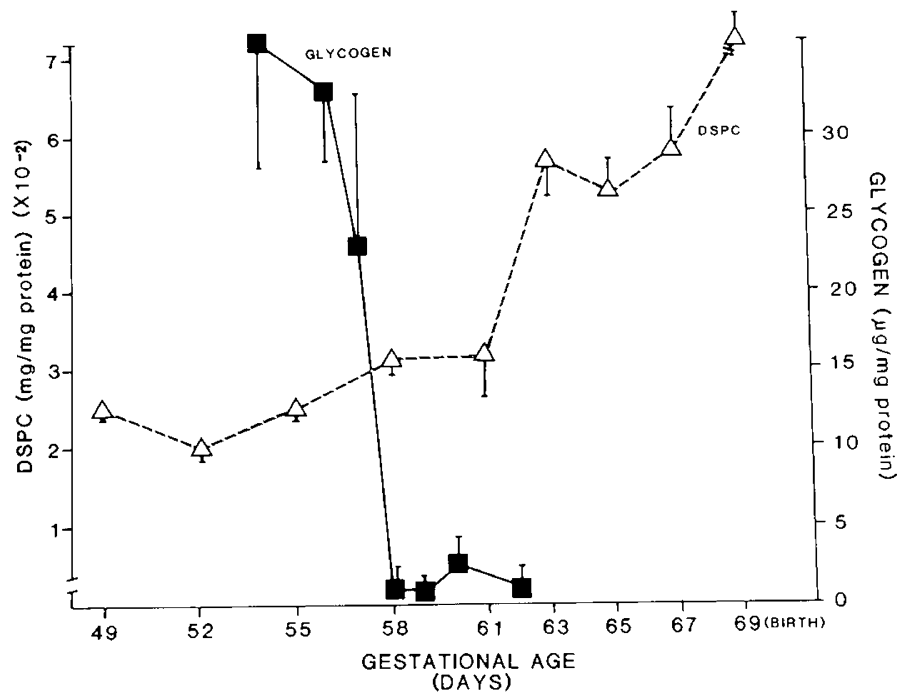

Fig. 2. Changes in lung tissue glycogen and DSPC content in developing guinea pig lung. Each point represents a total of three to six lungs. Change in glycogen between day 57 and 58, significant at $p<0.05$. Change in DSPC from day 61 to 63 , significant at $p<0.01$. Values are mean $\pm \mathrm{SD}$. hormones demonstrate significant and concurrent peaks in their serum levels $(p<0.05)$. These hormonal elevations thus precede the elevation in lung DSPC and the initial appearance of PG which both occur at gestational day 61 (Figs. 2 and 4).

Survival of premature animals. The top curve in Figure 4 illustrates the survival rates of prematurely delivered guinea pigs. No premature guinea pig survival occurred prior to 61 days of gestation. At gestational days 61 and 63 (8 and 6 days before normal term, respectively), $53 \%(8 / 15)$ and $57 \%(8 / 14)$ of prematurely delivered guinea pigs survived for at least $24 \mathrm{~h}$ postresuscitation. This survival rate reached $77 \%(10 / 13)$ by 66 days of gestation ( 3 days premature); at this time DSPC (seen in Fig. 2) and PG (seen in the lower curve of Fig. 4) had both increased by $>50 \%$ above levels found in 61-day fetal animals and lung morphology had progressed to an advanced saccular stage with thin-walled airspaces and alveolar formation already apparent (Fig. $1 C$ and $D$ ).

\section{DISCUSSION}

The pattern of lung development in the fetal guinea pig is characterized by both similar and unique features when compared to the lung development of other commonly studied smallsized laboratory mammals. Lechner et al. (11) previously noted that newborn guinea pig lungs demonstrate a pattern of alveolarization that appears indistinguishable from the morphology of adult guinea pigs. In agreement with that study and with the work of Lechner and Banchero (3), our findings of saccularappearing airspaces by 58 days of gestation in the guinea pig, as well as remarkably thin and septated acinae in the newborn indicate that this species is "precocious" in its morphologic lung development. In this respect the developing guinea pig lung differs from that of the rat studied extensively by Burri et al. (12) and others (13) and found to have large diameter saccular structures but no detectable alveoli at birth. It also differs from the newborn rabbit (14), mouse (15), and hamster (16), each of which undergoes alveolarization postnatally. It has been suggested by Stith and Das (17) that the guinea pig (with its advanced in utero alveolarization) might be the preferred animal model for human lung development (17). The finding of precocious morphologic lung development in addition to the advanced physical

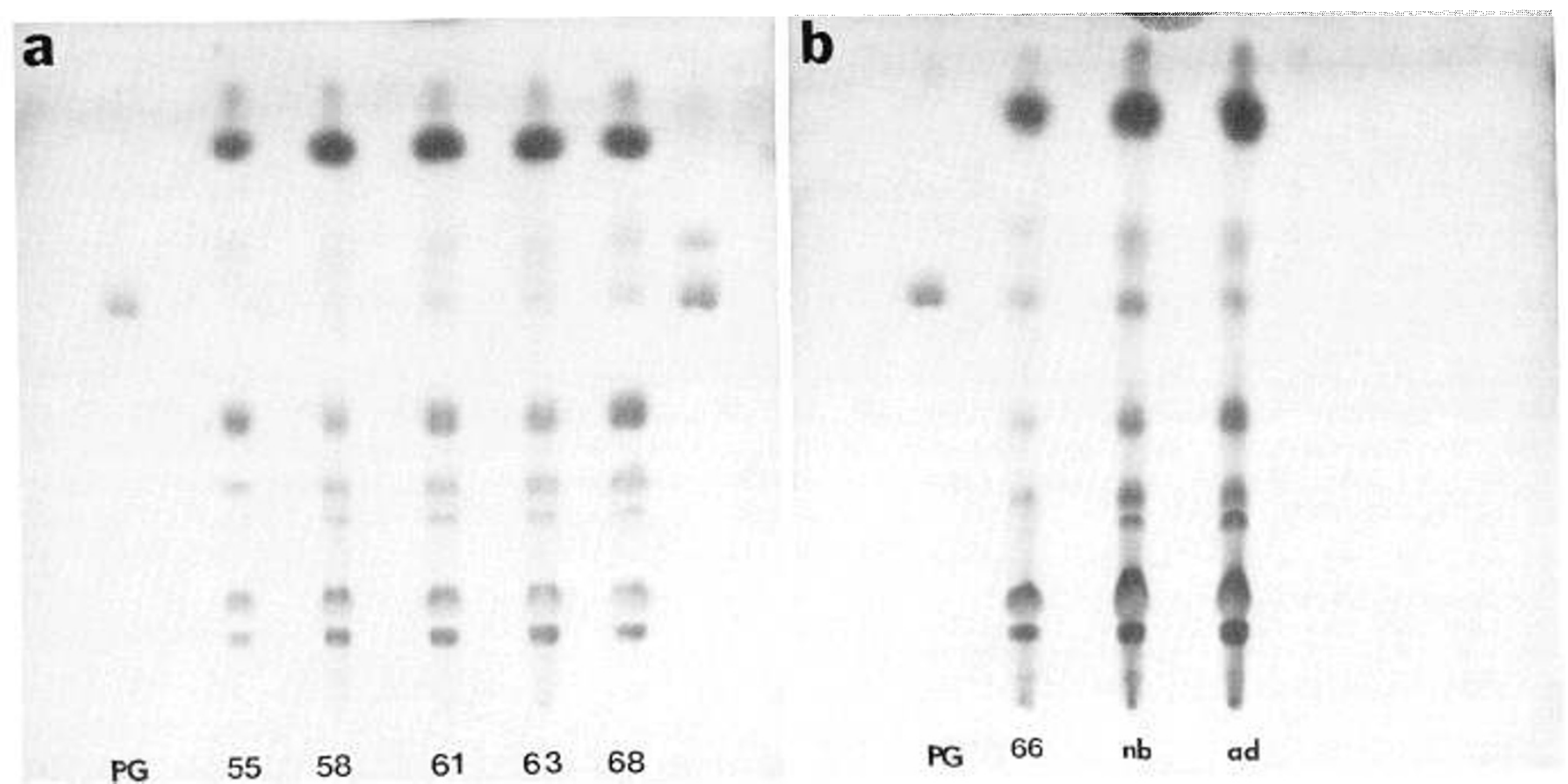

Fig. 3. a, thin-layer chromatogram of lung lipids from developing guinea pigs. Tracks (from left to right): PG standard, 55-, 58-, 61-, 63-, and 68 -day guinea pigs. $b$, thin-layer chromatogram of lung lipids from guinea pigs. Tracks (from left to right): PG standard, 66-day, newborn, and adult guinea pigs. 


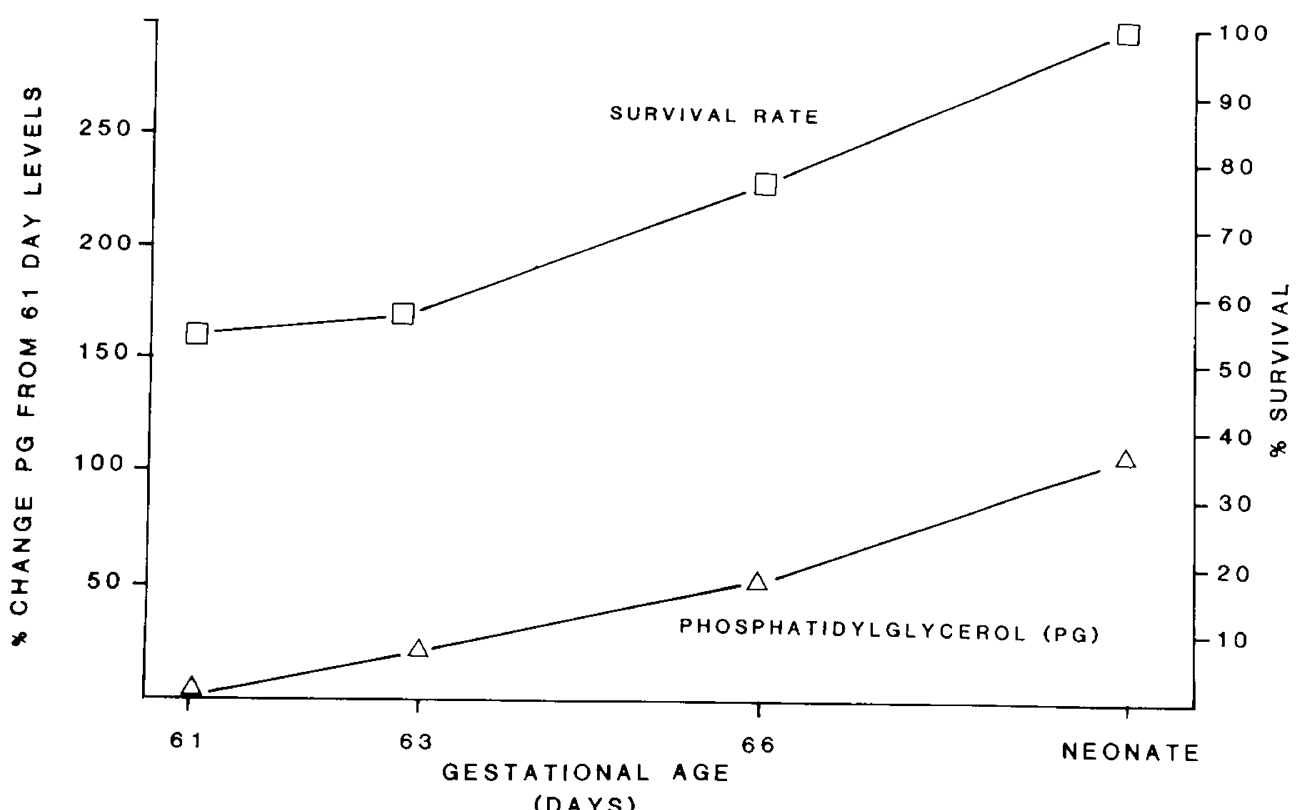

Fig. 4. Percent change in lung PG content compared to 61-day values (left ordinate) and survival rate in prematurely delivered guinea pigs from 61 days gestation until term (69 days) (right ordinate).

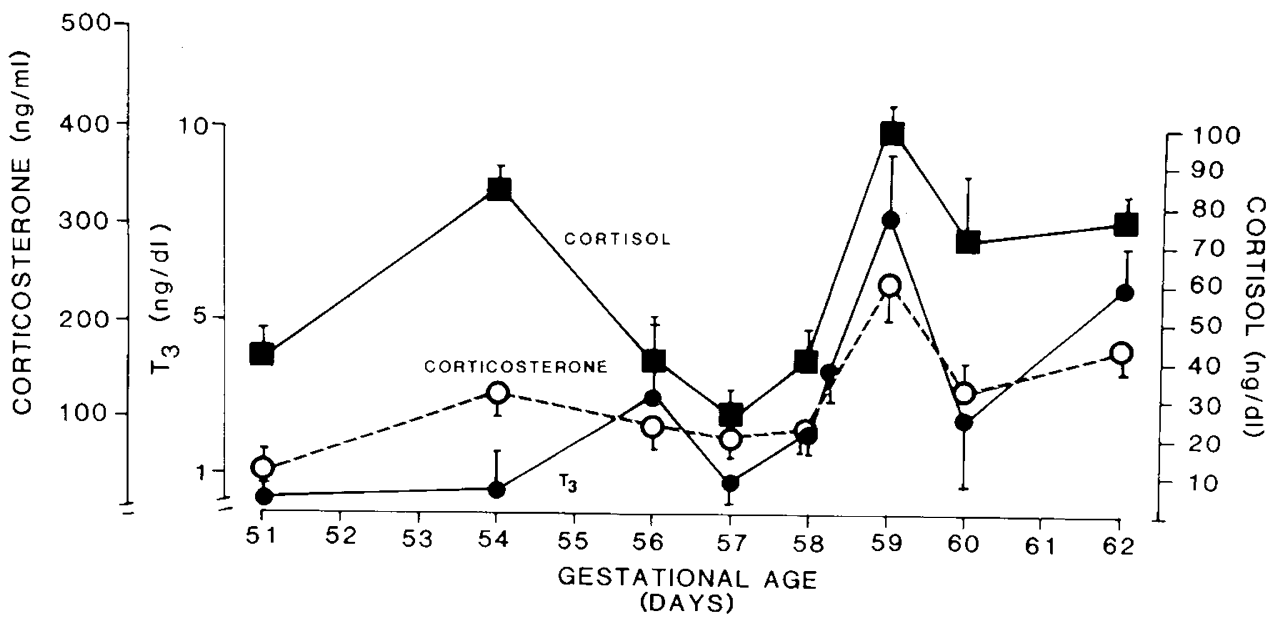

Fig. 5. Serum total cortisol, corticosterone, and $\mathrm{T}_{3}$ levels from fetal guinea pigs of 51-62 days of gestation. Each point represents two to five serum samples. Day 54 and day 59 peaks of cortisol and corticosterone are significantly increased $(p<0.05)$; values for $\mathrm{T}_{3}$ are significantly elevated at days 56 and $59(p<0.05)$. Values are mean \pm SD

features present in the newborn guinea pig is therefore consistent with the aforementioned hypothesis of Engel (2) that lung development should parallel the species' overall development at birth.

In contrast to the much advanced morphologic lung maturation, the development of the surfactant system in the guinea pig lung follows a pattern common to most other small-sized mammals. In the guinea pig, we found a dramatic and sustained fall in lung glycogen content around day 58 of gestation, followed by a sharp rise in whole lung DSPC content and the appearance of PG in the 61-day fetus. This decrease in lung tissue glycogen preceding the rise in surfactant is similar to what has been reported for fetal rabbits (18) and rhesus monkeys (19), suggesting but not proving that lung glycogen provides substrate for phospholipid (surfactant) synthesis in these species. The increases in DSPC and PG which begin $\sim$ day 61 in the fetal guinea pig are occurring at approximately $88 \%$ of the guinea pig gestation period. This chronology is very similar to the rapid increases in surfactant which occur in the 28-day fetal rabbit $(\sim 90 \%$ of gestation) (18), the day $14-15$ fetal hamster (87-94\% of gestation) (20), and the 20 -day fetal rat ( $~ 90 \%$ of gestation) (21). It is of interest that the pattern of surfactant maturation in the guinea pig contrasts with the pattern described for another "precocious" species, the spiny mouse (22). Despite a relatively long gestation period (39 days) in the spiny mouse, small litter size, and neonates with fur, open eyes, and ability to thermoregulate (features similar to the guinea pig), the prenatal surfactant surge is reported to occur even later and in a more protracted fashion in the spiny mouse than in the rat or guinea pig $(20,22)$.

We measured lung tissue phospholipid rather than lung lavage fluid levels of DSPC and PG in this study. For this reason our DSPC and PG values may be more representative of total surfactant DSPC and PG pools (intracellular plus intraalveolar) compared to lavage measurements, but will also represent other nonsurfactant-related sources of DSPC and PG present in the lung. In addition to the developmental pattern of lung lavage phospholipids, the development of the enzymes involved in surfactant synthesis was not explored in the present study.

Multiple studies have suggested that an endogenous glucocorticoid mechanism may play a role in surfactant development. Kitterman et al. (23) determined that a closer correlation was present in fetal sheep between plasma cortisol and DSPC increase than between gestational age and rise in DSPC. Receptor data 
indicating an increase in the number of glucocorticoid receptors in fetal lung prior to the onset of surfactant production (24), plus adrenocorticoid ablation (25) or blocking studies (metyrapone) (21) demonstrating delays in surfactant maturation, add additional support for an endogenous glucocorticoid influence on surfactant development. Our findings of serum glucocorticoid peaks (cortisol and corticosterone) in the 59-day guinea pig, preceding the DSPC/PG rise beginning at day 61 , are in agreement with studies from other species (23) and consistent with the guinea pig serum hormone data of Jones and Rolph (26). In addition to the role endogenous glucocorticoids may play in surfactant system maturation, there is good evidence in fetal sheep that morphologic lung development is also more closely related to fetal cortisol levels than to gestational age (23), suggesting this hormone may influence morphologic maturation as well. In the guinea pig we found the predominant peak in serum cortisol and corticosterone to be at 59 days, following the dramatic changes in lung morphology found to occur between 55 and 58 days of gestation. It is possible, however, that the earlier steroid peak in the guinea pig, occurring at day 54 , may be specifically influencing the changes in lung morphology seen over the next several days of gestation, without affecting the surfactant system at this time.

The role of endogenous thyroid hormone in surfactant and morphologic lung development is less firmly established than for glucocorticoids. Lines of evidence such as studies of Cunningham et al. (27) and Erenberg et al. (28), demonstrating delays in tracheal fluid lecithin/sphingomyelin ratios and retarded histologic lung maturation in thyroidectomized fetal sheep, do support the influence of thyroid hormone. The guinea pig does demonstrate an early $\mathrm{T}_{3}$ peak at 56 days, around the time of the major histologic progression of maturation, and a later peak at 59 days, preceding major changes in lung tissue DSPC and PG. In our study, the associations between thyroid and glucocorticoid hormones and morphologic and surfactant maturation are temporal ones and although suggestive, do not actually prove cause and effect relationships.

Our study demonstrated a greater than $50 \%$ survival for fetal guinea pigs delivered at 61 days ( $88 \%$ of gestation) and treated with no intensive care aside from immediate postnatal resuscitation. Survival for rats delivered 3 days prematurely $(86 \%$ of gestation) has been reported at $<10 \%$ (29). Similarly, the majority of rabbits delivered at 27.5 days ( $88 \%$ of gestation) will die without vigorous support (30). Thus, with respect to its premature survival, in addition to its morphologic lung maturation, the guinea pig appears precocious compared to other small mammals frequently utilized for lung development studies. By 61 days gestation when $>50 \%$ of prematurely delivered guinea pigs survive, lung morphologic development has advanced beyond lung biochemical development (with DSPC just beginning its rise at this time and PG only beginning to appear).

In summary, the maturation of the guinea pig is one of interesting contrasts. At birth after an extended period of gestation, the newborn guinea pig shows "precocious" physical, physiologic and morphologic maturity. If delivered prematurely at 61 days of gestation, more than half of these "premies" will survive. The prenatal guinea pig lung demonstrates dramatic changes in lung morphology significantly earlier than comparable species. The pattern of surfactant development, on the other hand, with antecedent hormone peaks and glycogen depletion, occurs at a time in gestation and with a pattern very much like that found in frequently studied "nonprecocious" small-sized mammals. With its prenatal alveolar formation and the capacity for premature survivability, the guinea pig may be a useful small-sized model for the study of lung development as well as the effect of various clinical interventions in the human premature infant.
Acknowledgments. The authors thank Mrs. Ondina GarciaPons for preparation of the manuscript and Mr. Miguel Martinez and Mr. Reynaldo Sio for their technical assistance and Dr. Donald Massaro for his helpful review of the manuscript.

\section{REFERENCES}

1. Wagner JE, Manning PJ 1976 The Biology of the Guinea Pig. Academic Press, New York; pp 1-4

2. Engel S 1953 The structure of the respiratory tissue in the newly-born. Acta Anat 19:353-365

3. Lechner A, Banchero N 1982 Advanced pulmonary development in newborn guinea pigs (Cavia porcellus). Am J Anat 163:235-246

4. Schacterle RE, Pollack RL 1973 A simplified method for the quantitative assay of small amounts of protein in biological material. Anal Biochem 51:654655

5. Bligh EF, Dyer WJ 1959 A rapid method of total lipid extraction and purification. Can J Biochem Physiol 37:911-917

6. Touchstone JC, Chen JC, Beaver KM 1980 Improved separation of phospholipids in thin layer chromatography. Lipids 15:61-62

7. Mason RJ, Nellenbogen J, Clements JA 1976 Isolation of disaturated phosphatidylcholine with osmium tetroxide. J Lipid Res 17:281-284

8. Morrison WR 1964 A fast, simple and reliable method for the microdetermination of phosphorus in biological materials. Anal Biochem 11:218-224

9. Schwartz AL, Rall TW 1973 Hormonal regulation of glycogen metabolism in neonatal rat liver. Biochem J 134:985-993

10. Fisher RA 1970 Statistical Methods for Research Workers. Hafner Press, New York, pp 213-301

11. Lechner AJ, Grimes MJ, Aquin L, Banchero N 1982 Adaptive lung growth during chronic cold plus hypoxia is age dependent. J Exp Zool 219:255-291

12. Burri PH 1974 The postnatal growth of the rat lung. III. Morphology. Anat Rec 180:77-98

13. Burri PH, Dbaly J, Weibel ER 1974 The postnatal growth of the rat lung. I. Morphometry. Anat Rec 178:711-730

14. Kikkawa Y, Motoyama EK, Gluck L 1968 Study of the lungs of fetal and newborn rabbits. Morphologic, biochemical and surface physical development. Am J Pathol 52:177-210

15. Amy RW, Bowes D, Burri PH, Haines J, Thurlbeck WM 1977 Postnatal growth of mouse lung. J Anat 124:131-151

16. Crocker TT, Teeter A, Nielson B 1970 Postnatal cellular proliferation in mouse and hamster lung. Cancer Res 30:357-361

17. Stith I, Das SK 1982 Development of cholinephosphotransferase in guinea pig lung mitochondria and microsomes. Biochim Biophys Acta 714:250-256

18. Khosla SS, Brehrer A, Eisenfeld AJ, Ingelson LD, Parks PA, Rooney SA 1983 Influence of sex hormones on lung maturation in the fetal rabbit. Biochim Biophys Acta 750:112-116

19. Perelman RH, Engle MJ, Kemnitz JW, Kotas RV, Farrell PM 1982 Biochemical and physiological development of the fetal rhesus lung. J Appl Physiol 53:230-235

20. Sosenko I, Frank L 1985 Preparation for birth of the fetal lung antioxidant enzymes in four species. Am Rev Respir Dis 13:A237

21. Sosenko IRS, Lewis PL, Frank L 1986 Metyrapone delays surfactant and antioxidant enzyme maturation in developing rat lung. Pediatr Res 20:672675

22. Oosterhuis WP, Mooren PG, Charles R, Lamers WH 1984 Perinatal development of the lung in rat and spiny mouse: its relation to altricial and precocial timing of birth. Biol Neonate 45:236-243

23. Kitterman JA, Liggins GC, Campos GA, Clements JA, Forster CS, Lee CH, Creasy RK 1981 Prepartum maturation of the lung: relation to cortisol. J Appl Physiol 51:384-390

24. Ballard PL, Ballard RA 1974 Cytoplasmic receptor for glucocorticoids in the lung of the human fetus and neonate. $\mathrm{J}$ Clin Invest 53:477-486

25. Liggins GC, Kitterman JA, Campos GA, Clements JA, Forster CS, Lee CH, Creasy RK 1981 Pulmonary maturation in the hypophysectomized ovine fetus. Differential response to adrenocorticotropin and cortisol. J Dev Physiol 3:1-14

26. Jones CT, Rolph TP 1982 Metabolic events associated with the preparation for independent life. In: The Fetus and Independent Life. Ciba Foundation Symposium no. 86, Pitman, London, pp 214-223

27. Cunningham MD, Hollingsworth DR, Belin RP 1980 Impaired surfactant production in cretin lambs. Obstet Gynecol 55:439-443

28. Erenberg A, Rhodes ML, Weinstein MM, Kennedy RL 1979 The effect of thyroidectomy on ovine fetal lung maturation. Pediatr Res 13:230-235

29. Frank L, Roberts RJ 1979 Effect of low dose prenatal corticosteroid administration of the premature rat. Biol Neonate 36:1-9

30. Sosenko IR, Lawson EE, Demottaz V, Frantz ID III 1980 Functional delay of lung maturation in fetuses of alloxan diabetic rabbits. J Appl Physiol 48:643647 